\title{
Educación, barbarie y ley natural en Bartolomé de las Casas y José de Acosta
}

\author{
Víctor ZORRILLA ${ }^{\mathrm{i}}$
}

\section{RESUMEN}

En el ámbito de las controversias indianas, un tema que ocupó la atención de los autores fue la educación de los indios, entendida en primera instancia como el procedimiento para lograr en ellos la superación de la barbarie, o sea, una adecuación más perfecta a la ley natural. El tratamiento de este tema dio origen a una auténtica filosofía de la educación que, inspirada en la cuestión indiana, posee valor universal en virtud de la profundidad antropológica de su planteamiento y su enfoque clásico. En este trabajo se estudia la articulación de las nociones de barbarie, educación y ley natural en la obra pedagógica de Bartolomé de las Casas y José de Acosta.

PALABRAS CLAVE: educación, barbarie, ley natural, Las Casas, Acosta

\begin{abstract}
In the Spanish-Indian controversies, special attention was given to the subject of the education of the Indians, understood in a first approach as the necessary procedure to enable them to overcome their barbarianism, that is, to better adapt themselves to the natural law. This generated a philosophy of education which, in spite of being directly inspired by the circumstances of the Indians, nonetheless had permanent value by virtue of its anthropological soundness and its classical approach. This article deals with the notions of barbarianism, education, natural law, and their interplay in the educational works of Bartolomé de las Casas and José de Acosta.
\end{abstract}

KEYWORDS: education, barbarianism, natural law, Las Casas, Acosta

\section{Consideraciones preliminares}

Uno de los principales problemas que fueron objeto de las controversias indianas -y quizá el más estudiado- fue, como se sabe, el de la legitimidad de la guerra contra los indios, generador de una discusión que alcanzó su dramático clímax en la famosa Controversia de Valladolid (1550-1551) entre Juan Ginés de Sepúlveda y Bartolomé de las Casas ${ }^{1}$. Sin embargo, otro tema que ocupó la atención de los teólogos, de manera persistente aunque más discreta en sus manifestaciones, fue el de la educación de los indios. Se trata, en realidad, de un tema más amplio que puede decirse que engloba al primero, o por lo menos le es concomitante y complementario. Pues la empresa indiana fue concebida desde el inicio, al menos en parte, como una tarea misional y, por ende, pedagógica. Había

\footnotetext{
${ }^{1}$ Pueden verse las líneas generales de la polémica en: VÍCTOR ZORRILLA, El estado de naturaleza en Bartolomé de las Casas, Pamplona, Servicio de Publicaciones de la Universidad de Navarra, 2010, 87-100.
} 
que enseñar la fe a los indios, para lo cual debían propiciarse antes las condiciones naturales -físicas, culturales, psicológicas, morales- requeridas para el tránsito del ámbito meramente natural en el que se encuentran los infieles al ámbito sobrenatural de la gracia. Algunos propusieron el empleo de medios bélicos como medida auxiliar para facilitar o acelerar este tránsito: se precisaba extirpar los vicios -la idolatría, el sacrificio humano, la antropofagia- con la ayuda de las armas, si era necesario, para allanar el camino a la predicación; la intervención militar había de garantizar, asimismo, la protección de los misioneros ${ }^{2}$. Belicistas o no, todos los autores coincidían en que la recepción de la fe exigía, como requisito previo por parte de los indios, un mínimo de respeto a la ley natural. La discrepancia entre unos y otros se hallaba precisamente en los medios que consideraban idóneos para llegar a cumplir este requisito, que podría plantearse también, negativamente, como la superación de la barbarie.

Puede afirmarse, por lo anterior, que el tema de fondo de las «Controversias indianas», más que una cuestión meramente jurídica -relativa al derecho de guerra o al derecho de «intervención humanitaria»-, consistía fundamentalmente en una cuestión pedagógica, al menos en el sentido de que se trataba de una discusión relativa al modo más adecuado de preparar a los indios, en el ámbito natural, para la recepción de la fe sobrenatural, así como al modo más eficaz (y válido) de transmitir esta fe.

La atención a este tema produjo algunas obras notables de pedagogía que, aunque tenían un fin último misionológico, pueden considerarse con todo derecho trabajos logrados de filosofía de la educación; tal es el caso del tratado Rethorica Christiana ${ }^{3}$ de Fray Diego Valadés, del De procuranda indorum salute de José de Acosta y el De unico vocationis modo de Bartolomé de las Casas. Me centraré en la obra de estos dos últimos autores para estudiar el perfil que presentan del receptor de la educación, o sea, el indio, caracterizado a grandes rasgos - con los matices y analogías que veremos enseguida- por medio de la noción de bárbaro ${ }^{4}$, y también para examinar, consiguientemente, la concepción que sostienen del carácter y sentido de la obra educativa.

2 Cfr. JUAN GINÉS DE SEPÚlVEDA, Demócrates Segundo o de las justas causas de guerra contra los indios, Madrid, CSIC - Instituto Francisco de Vitoria, 1984, 20-22, 29-31, 33, 39, 42, 44, 62-63, 67-68. Sepúlveda tenía redactada esta obra hacia 1545.

${ }^{3}$ FRAY DIEGO VALADÉS, Retórica cristiana, México, Fondo de Cultura Económica, 2003. Publicado originalmente con el título de Rethorica Christiana en Perusa, Italia, el año de 1579.

${ }^{4}$ Aunque habitual en la terminología americanista, prefiero obviar el uso de la expresión «el Otro» (y sus derivados) para referirme al objeto de las disquisiciones de estos autores, sobre todo por dos razones. En 


\section{La persuasión del entendimiento: Bartolomé de las Casas}

A propósito justamente de su polémica con el humanista Juan Ginés de Sepúlveda, Bartolomé de las Casas desarrollará una noción analógica de la noción de bárbaro a través de la cual buscará transmitir una comprensión adecuada de la realidad antropológica americana. En el texto fundamental de la polémica, la Apología 5 -así como en su Apologética historia sumaria ${ }^{6}$, Las Casas explica que el término bárbaro tiene cuatro sentidos. En primer lugar, se llama bárbaro en sentido amplio a cualquiera que, por algún vicio o depravación grave, se aleja de la ley natural e incurre en acciones inicuas o crueles, aunque sea de manera incidental o episódica. En segundo lugar, e impropiamente también, se llaman bárbaros aquellos pueblos que hablan una lengua extraña o que no tienen escritura. Así, por ejemplo, los griegos llamaban bárbaros a cualquier pueblo que no hablara el griego. En tercer lugar están los bárbaros propiamente dichos, quienes, ajenos a todo comportamiento virtuoso y aun razonable, viven insocialmente: sin leyes, sin instituciones, sin religión y sin cultura ${ }^{7}$. Por último, pueden considerarse bárbaros todos los infieles, pues, al desconocer la doctrina evangélica, que es ley perfecta, incurren en muchos vicios y torpezas que sólo pueden ser corregidos mediante la predicación del evangelio ${ }^{8}$.

Las Casas refiere siempre el concepto de bárbaro, pues, a cierta privación, ya sea del autodominio (primer sentido), del lenguaje (segundo sentido), de la razón -y, por ende, de

primer lugar -aunque este motivo sea incidental y no determinante-, para respetar la terminología que ellos mismos utilizan. Pero, principalmente, porque me parece que aquel vocablo resulta desorientador respecto a la sustancia del pensamiento de la mayoría de autores del Siglo de Oro español, en quienes no predomina la percepción «culturalista» (por más que pudiera ser un condicionante) sino la cristiana: ellos veían en el indio a un prójimo, potencial hermano en la fe, más que a un «Otro».

${ }^{5}$ Cito por la edición crítica bilingüe de Ángel Losada: BARTOLOMÉ DE LAS CASAS, Apología, en: Obras completas de Bartolomé de las Casas, vol. 9, Madrid, Alianza, 1988. La polémica de Valladolid (para la cual Las Casas preparó el texto) se llevó a cabo en 1550-1551.

6 LAS CASAS, Apologética historia sumaria, en: Obras completas de Bartolomé de las Casas, vols. 6-8, Madrid, Alianza, 1992. Las Casas inició la redacción de esta obra en torno a 1552 (desgajándola de su Historia de las Indias, de la que originalmente formaba parte) y la terminó en 1557.

${ }^{7}$ LAS CASAS, Apología, cc. 1-2, Obras completas, vol. 9, 80-82, 86-94; Apologética historia, cc. 264-265, Obras completas, vol. 8, 1576-1582.

${ }^{8}$ LAS CASAS, Apología, c. 5, Obras completas, vol. 9, 118-122; Apologética historia, cc. 266-267, Obras completas, vol. 8, 1583-1590. 
la vida en sociedad (tercer sentido)- o de la fe (cuarto sentido) ${ }^{9}$. Sólo los que se llaman bárbaros en el tercer sentido lo son en sentido estricto; los demás se denominan así por algún rasgo en el que se asemejan a ellos $^{10}$. Y los indios no pertenecen, ciertamente asegura Las Casas-, a esta clase de bárbaros, pues viven políticamente, con gobiernos legítimos y leyes; tienen comercio entre ellos, practican la religión, ejercen oficios y hacen todas las cosas necesarias a la vida social ${ }^{11}$. Algunos, quizá, pudieran llamarse bárbaros en el primer sentido - por tener algunas costumbres depravadas o crueles ${ }^{12}$ - pero, en ese caso, habría que extender el calificativo a muchos españoles también, por la inhumanidad con que han tratado a los indios ${ }^{13}$. Podrían, asimismo, considerarse bárbaros en el segundo sentido - por no hablar castellano-, pero en tal caso habría que reconocer que los españoles serían igualmente bárbaros para ellos, por no conocer sus lenguas ${ }^{14}$. En el cuarto sentido -por ser infieles- está claro que los indios deben llamarse bárbaros, pero en este mismo sentido impropio deben llamarse bárbaros también todos los pueblos de la antigüedad indoeuropea ${ }^{15}$.

Cabría considerar, por tanto, dos maneras de proceder en relación con los bárbaros, según éstos lo sean en sentido estricto o impropio. Y aunque Las Casas excluye o limita al máximo la existencia de bárbaros en sentido estricto entre los indios -y en la humanidad en general ${ }^{16}$, no por ello deja de indicar cómo debe actuarse con ellos: todos pueden ser atraídos -asegura-, mediante una amistosa persuasión, a la vida civil ${ }^{17}$. Recurriendo a la historia antigua, cita los ejemplos de la labor civilizadora que supuestamente llevaron a

${ }^{9}$ Cfr. VALERIA MARTIJA, «Algunas consideraciones sobre el concepto de 'bárbaro' en el artículo primero de la Apología de Fray Bartolomé de las Casas», en: Sandra Anchondo Pavón (comp.), Historia y destino de la filosofía clásica novohispana. Un recorrido a través de sus pensadores y de sus textos, México, Los Libros de Homero, 2007, 134.

${ }^{10}$ LAS CASAS, Apología, c. 5, Obras completas, vol. 9, 122; Apologética bistoria, Epílogo, Obras completas, vol. 8, 1590-1591.

${ }^{11}$ LAS CASAS, Apologética historia, Epílogo, Obras completas, vol. 8, 1591.

12 Ibid.

${ }^{13}$ LAS CASAS, Apología, c. 5, Obras completas, vol. 9, 122.

${ }^{14}$ LAS CASAS, Apologética historia, Epílogo, Obras completas, vol. 8, 1591.

${ }^{15}$ Ibid.

${ }^{16}$ Ello se debe a que Las Casas considera imposible que la naturaleza y, por ende, su Creador providente, yerren de manera sistemática o generalizada: «Como si la Divina Providencia en la creación de tan innumerable número de ánimas racionales se hubiera descuidado, dejando errar la naturaleza humana, por quien tanto determinó hacer y hizo, en tan cuasi infinita parte como esta es del linaje humano, a que saliesen todas insociales y por consiguiente monstruosas, contra la natural inclinación de todas las gentes del mundo; no permitiendo que yerre así alguna especie de las otras corruptibles creaturas, sino alguna por maravilla de cuando en cuando». LAS CASAS, Apologética historia, Argumento, Obras completas, vol. 6, 285. 17 LAS CASAS, Apologética historia, cc. 46-48, Obras completas, vol. 7, 526-538. 
cabo Lisanias y Saturno entre griegos y romanos, para mostrar que ningún pueblo, por culto que llegara a ser, se vio libre de cierta «barbarie primitiva»: «los atenienses, entre los cuales tanto resplandeció la philosophía, las sciencias naturales y morales y toda buen doctrina, fueron al principio rudísimos y barbarísimos y tenidos como otras naciones por bestias; porque no nascieron más que las otras enseñados ni políticos $\gg^{18}$. No hay, pues, hombres incorregibles, y por tanto, el afán civilizador no justifica el uso de la violencia. La persuasión, por el contrario, en cuanto instrumento argumentativo dirigido a la razón y a la voluntad, respeta la índole racional de aquel a quien se dirige, como veremos enseguida.

La argumentación a favor de la postura «belicista» presupone en los indios, entonces, la condición de bárbaros en sentido estricto -que equivale a la de «siervos por naturaleza» de la doctrina aristotélica en que Sepúlveda se basa ${ }^{19}$, , misma que Las Casas les niega. Pero otros dos tipos de barbarie - la pérdida incidental del autodominio y la privación de la fe-conllevan todavía alguna desviación respecto del dictamen de la recta razón. De ahí que la barbarie «relativa» de los indios -que Las Casas no niega- también haga necesaria una labor pedagógica que les permita adecuarse más perfectamente a este dictamen de la recta razón que constituye la ley natural. Ello no significa que Las Casas sostenga una visión reductiva o excluyente de la ley natural, según la cual sólo los españoles o europeos se adecuarían a ella -su crítica acérrima del comportamiento de éstos con los indios a lo largo de su obra bastaría para desmentir tal suposición-; por el contrario, Las Casas admite que la racionalidad humana puede manifestarse de diversas maneras, de forma que no habría por qué cambiar o eliminar de las culturas indígenas aquello que tuvieran de positivo $^{20}$.

En realidad, Las Casas reconoce que hay cierta gradación en el desarrollo moral e intelectual de las distintas sociedades indígenas (y de las sociedades paganas en general). Así, algunos pueblos estarían mejor preparados -al menos, por lo que respecta a su disposición natural- para recibir el mensaje evangélico, gracias a que han conseguido un desarrollo más completo de las virtualidades inherentes a la naturaleza humana. Desde luego, esta naturaleza es idéntica en todos -tesis fundamental del pensamiento

\footnotetext{
${ }^{18}$ LAS CASAS, Apologética historia, c. 48, Obras completas, vol. 7, 535.

${ }_{19}$ ARISTÓTELES, Politica, I, 2, 1252a 24 - 1252b 9 (ARISTOTLE, The Complete Works of Aristotle, vol. 2, Jonathan Barnes, ed. Princeton-Chichester, Princeton University Press, 1984, 1986-1987).

${ }^{20}$ LAS CASAS argumenta indirectamente en este sentido, por ejemplo, en: Apologética historia, c. 213, Obras completas, vol. 8, 1355.
} 
lascasiano ${ }^{21}$-; lo que varía es el grado de desenvolvimiento de las virtualidades latentes en ella. Pues bien: para Las Casas, los indios han desplegado estas virtualidades naturales particularmente en el ámbito de la religión. No es que Las Casas ignore las aberraciones de algunas religiones indígenas - describe detalladamente los sacrificios humanos de los aztecas y menciona los de otros pueblos mesoamericanos ${ }^{22}-$, pero considera que, en general, estas religiones muestran un refinamiento ritual y una ascesis a tal grado exigente, que representan una culminación en el desarrollo evolutivo de la religión natural (como distinta de la religión revelada o sobrenatural) ${ }^{23}$. Así, los indios estarían ya próximos, por su disposición natural -y supuesta la actuación de la gracia-, para convertirse a la fe ${ }^{24}$.

21 «Todas las naciones del mundo son hombres y de todos los hombres y de cada uno de ellos es una no más la definición, y ésta es que son racionales». LAS CASAS, Apologética bistoria, c. 48, Obras completas, vol. 7,536 .

22 Véase: LAS CASAS, Apologética historia, cc. 169-172, Obras completas, vol. 8, 1162-1173; cc. 174-179, Obras completas, vol. 8, 1176-1201; c. 183, Obras completas, vol. 8, 1215-1218; y c. 185, Obras completas, vol. 8, 12241229. Mostrando una gran solvencia histórica y antropológica, Las Casas tampoco ignora la práctica de los sacrificios humanos en la antigüedad indoeuropea, incluso grecolatina (cfr. v. gr. LAS CASAS, Apologética bistoria, cc. 147-149, Obras completas, vol. 7, 984-997). Para él, este hecho demuestra el efecto purificador que la doctrina cristiana ha tenido tanto en la antigüedad pagana como en el Nuevo Mundo: «Y en todas partes, hasta los tiempos de Nuestro Salvador, con muerte de animales y de hombres y con turpísimas otras suciedades se solían aplacar los demonios y ofrecerles sacrificios, y en ninguna parte aquellas abominaciones cesaron antes que alumbrase el mundo la doctrina de Jesuchristo. [...] Donde parece que la medicina verdadera para sacar tan grande pestilencia no fue otra por todo el mundo sino la predicación evangélica». LAS CASAS, Apologética historia, c. 162, Obras completas, vol. 8, 1129; cfr. Apologética bistoria, c. 82, Obras completas, vol. 7, 687, y c. 161, Obras completas, vol. 8, 1123-1127. He estudiado la interpretación lascasiana de los sacrificios humanos en ZORRILLA, El estado de naturaleza en Bartolomé de las Casas, 93-100. ${ }_{23}$ «En lo tocante a la religión, dioses, templos, sacerdotes y sacrificios ninguna o cuasi ninguna de las [naciones] gentiles antiguas les llegó al zapato [a las naciones indias] y, por consiguiente, muy mejor y más prudente, discreta, razonable, honesta y comedidamente que todas, ya que padecían la ignorancia y error común del verdadero Dios [...], usaron de la razón natural». LAS CASAS, Apologética bistoria, c. 195, Obras completas, vol. 8, 1269; cfr. Apologética historia, c. 169, Obras completas, vol. 8, 1162; Apologética historia, cc. 188191, Obras completas, vol. 8, 1240-1256.

${ }^{24}$ LAS CASAS, Apologética historia, c. 263, Obras completas, vol. 8, 1571-1572. «Podríamos aquí considerar y detenernos considerando cuánto era el cuidado y solicitud que aquellas gentes de su religión y del servicio de sus dioses y dedicarles sus obras tenían. Y que si son en la fe christiana instruidas, donde con tan menos trabajo y costa nuestro verdadero Dios quiere ser servido, con cuánta mejor gana le sirvieran y cuánta ventaja en ello nos harían». LAS CASAS, Apologética historia, c. 179, Obras completas, vol. 8, 1201. «Bajo el terrible y sangriento aspecto de estos ritos -comenta Lewis Hanke-, Las Casas descubría un encomiástico espíritu de devoción, que podía ser dirigido a fines más elevados y ganarse para el servicio del único Dios verdadero». LEWIS HANKE, Bartolomé de las Casas. Pensador político, historiador, antropólogo, La Habana, Sociedad Económica de Amigos del País, 81. Hanke se refiere no sólo a los sacrificios humanos, sino también a las terribles penitencias que se autoinfligían algunos indios; véase: LAS CASAS, Apologética historia, cc. 172-174, Obras completas, vol. 8, 1170-1172, 1174-1177. Cfr. ANTHONY PAGDEN, The fall of natural man. The American Indian and the origins of comparative ethnology, Cambridge-Nueva YorkMelbourne, Cambridge University Press, 1986, 140-144. 
En su obra De unico vocationis modo $0^{25}$, Las Casas desarrolla una "pedagogía de la fe» que puede considerarse una verdadera teoría educativa en el sentido más amplio del término (trascendiendo, por tanto, su enfoque primordialmente doctrinal o misionológico), basada en el principio básico de la necesidad, para la tarea educativa, de la persuasión de la inteligencia y la atracción de la voluntad. Las Casas busca así oponer, a la coacción física y la violencia de la imposición por las armas, una pedagogía que respete la naturaleza racional y libre de los educandos ${ }^{26}$. La argumentación de Las Casas tiene diversos puntos de partida que llegan a la misma conclusión sobre la naturalidad de la educación auténticamente tal, que es aquella que va dirigida a la inteligencia y la voluntad. El carácter intrínsecamente violento o no natural de la coacción física en la educación queda así de manifiesto, pues la adquisición del conocimiento requiere de cierta tranquilidad de ánimo para que la razón pueda discurrir, con ayuda del maestro, de lo conocido a las verdades por conocer. El aprendizaje requiere asimismo que la voluntad se aficione de algún modo a su objeto, lo cual no puede ocurrir sino libremente. Y tanto el discurso de la razón como la afición de la voluntad requieren de un cultivo sosegado y más o menos extendido a través del tiempo. La inadecuación radical de la violencia o la coacción en la tarea pedagógica estriba en que el sosiego de ánimo necesario para búsqueda de la verdad no debe verse perturbado por afecciones anímicas fuertes o vehementes, tales como el temor, la angustia o la pena ${ }^{27}$.

La enseñanza requiere, por otro lado, que se empleen en alguna medida las reglas de la retórica, sobre todo en las materias difíciles. Y la retórica va encaminada a captar la simpatía y benevolencia de los oyentes, para lo cual emplea métodos persuasivos del

\footnotetext{
25 LAS CASAS, De unico vocationis modo omnium gentium ad veram religionem, en: Obras completas de Bartolomé de las Casas, vol. 2, Madrid, Alianza, 1990. Se citará por esta edición, señalando capítulo, parágrafo y páginas. La obra fue escrita aparentemente entre 1524-5 y 1526 (ISACIO PÉREZ FERNÁNDEZ, «Sobre la fecha de redacción del 'primer libro' de Fray Bartolomé de las Casas: De unico vocationis modo omnium gentium ad veram religionem», Ciencia Tomista, 105 (1978), 125-143) y constaba muy probablemente de dos libros; se conserva sólo una parte del primero. Las Casas incidirá de nuevo en algunos puntos tocados ahí en su obra tardía De thesauris (terminada probablemente hacia 1563), en: Obras completas de Bartolomé de las Casas, vol. 11.1, Madrid, Alianza, 1992.

26 «Modus naturalis movendi et dirigendi res naturales ad bonum proprium naturale est ut moveantur et dirigantur seu trahantur secundum uniuscuiusque modum et naturam [...]. Sed creatura rationalis apta nata est moveri, duci, dirigi et trahi blande, dulciter, leniter atque suaviter, propter arbitrii libertatem, ut voluntarie auscultet, voluntarie obediat, voluntarie haereat et serviat». LAS CASAS, De unico vocationis modo, V, 2, Obras completas, vol. 2, 24.

${ }^{27}$ LAS CASAS, De unico vocationis modo, V, 3, Obras completas, vol. 2, 36-42; De thesauris, c. XIV, Obras completas, vol. 11.1, 172-174.
} 
entendimiento y excitativos de la voluntad ${ }^{28}$. Las Casas se hace eco, así, de la recomendación pedagógica clásica según la cual sólo se aprende adecuadamente aquello en lo cual el discípulo muestra un interés espontáneo y verdadero ${ }^{29}$. De parte del discípulo es necesario, asimismo, que deposite su confianza en el maestro, aun cuando en un principio no comprenda totalmente las razones a través de las cuales éste le instruye en la ciencia $^{30}$. Y el maestro, por su parte, ha de enseñar paulatinamente, de lo fácil a lo difícil, considerando que la ciencia no puede aprenderse toda de golpe: hay que proceder de lo imperfecto a lo perfecto ${ }^{31}$. En el mismo afán, el maestro no debe rehuir, si fuera necesario, las repeticiones, incluso continuas, pues la costumbre, que es como una segunda naturaleza, hace que lo que en un principio parecía extraño, arduo o ajeno, se llegue a percibir como propio y cercano. Y nada de esto puede hacerse intempestiva ni violentamente, pues requiere de un trabajo paciente y prolongado, desarrollado en un ambiente de paz exterior y tranquilidad de ánimo ${ }^{32}$.

Además de estos argumentos en el plano natural, Las Casas recurre a ejemplos de la Sagrada Escritura para ilustrar su visión de la educación. Trae a cuento, así, a los padres antediluvianos del Antiguo Testamento y a los patriarcas anteriores a la Ley, todos los cuales emplearon la exhortación paternal como método predilecto para inculcar en sus hijos el culto del Dios verdadero y las buenas costumbres. Lo mismo cabe decir de Moisés, Samuel, Salomón y los profetas. La exhortación paternal es asimismo la fórmula habitual en los libros sapienciales, en los cuales se llama «hijos» a los destinatarios y se trata el tema de manera persuasiva y atractiva ${ }^{33}$. El mismo Cristo ordenó a sus discípulos que hicieran grandes beneficios a sus oyentes -sanar enfermos, resucitar muertos, limpiar

${ }^{28}$ LAS CASAS, De unico vocationis modo, V, 5, Obras completas, vol. 2, 52-56; De thesauris, c. XIV, Obras completas, vol. 11.1, 174. Las Casas se basa en CICERÓN, De Oratore, II, \$27 (CICERO, De oratore, Londres-Cambridge (Mass.), William Heinemann-Harvard University Press, 1967, 280).

29 PLATÓN, República, 536d - 537a (Platón, Diálogos, IV. República, Madrid, Gredos-RBA, 2007, 375-376). «La exigencia que pone Las Casas en esta retórica (una retórica que se dirige al entendimiento y a la voluntad) -comenta Mauricio Beuchot- es un signo de aprecio y respeto por las facultades naturales del hombre, tanto cognoscitivas como volitivas o afectivas. Ambas realizan y cumplen la intencionalidad global del hombre -i.e. la del conocimiento y la del deseo-, y con ello se está dando al hombre que se tiene enfrente (en este caso a los indios) un rango de respeto que abarca tanto su entendimiento como su voluntad; es un respeto radical a su intencionalidad, y por ello un respeto esencial a su persona». MAURICIO BEUCHOT, Los fundamentos de los derechos bumanos en Bartolomé de las Casas, Barcelona-Bogotá, Anthropos, 1994, 69.

${ }^{30}$ LAS CASAS, De unico vocationis modo, V, 6, Obras completas, vol. 2, 58.

${ }^{31}$ LAS CASAS, De unico vocationis modo, V, 7, Obras completas, vol. 2, 76-78.

32 LAS CASAS, De unico vocationis modo, V, 9, Obras completas, vol. 2, 92-96; De thesauris, c. XIV, Obras completas, vol. 11.1, 176-178.

${ }^{33}$ LAS CASAS, De unico vocationis modo, V, 11-14, Obras completas, vol. 2, 106-158. 
leprosos, expulsar demonios-y, además, hacerlo gratis. Así, al ver éstos que recibían tales bienes sin que los cristianos buscaran medrar, les cobrarían gran amistad y serían dóciles a su doctrina ${ }^{34}$. El ejemplo de vida constituye para Las Casas, por lo demás, el instrumento pedagógico más eficaz; por ello, antes debe el maestro cuidar su conducta que sus palabras $^{35}$.

\section{La adaptación al discípulo: José de Acosta}

En el proemio a su tratado misionológico De procuranda indorum salute ${ }^{36}$, Acosta, reconociendo la gran variedad de culturas indígenas americanas, aclara que hablará principalmente de lo que cabe aplicar a los indios peruanos. Y, para ubicarlos en el contexto general de la civilización humana, establece su propia tipología de la barbarie, una clasificación de carácter histórico más que conceptual ${ }^{37}$, cuyas implicaciones pedagógicas desarrollará a lo largo de la obra. Aunque sus reflexiones e indicaciones se refieren principalmente, como en el caso de Las Casas, a la pedagogía de la fe, su validez puede extenderse al ámbito de la educación en general.

Acosta empieza estableciendo o, más bien, dando por buena la definición tomasiana de bárbaro, a saber: aquél que se aparta de la recta razón y de la práctica habitual de los hombres $^{38}$. Y asegura que, tras un concienzudo examen de las sociedades indianas -tanto de las Indias Orientales como Occidentales-, éstas pueden reducirse a tres tipos fundamentales de bárbaros ${ }^{39}$ :

\footnotetext{
${ }^{34}$ LAS CASAS, De unico vocationis modo, V, 15-16, Obras completas, vol. 2, 160-176.

35 LAS CASAS, De thesauris, c. XIII, Obras completas, vol. 11.1, 160-170.

36 JOSÉ DE ACOSTA, De procuranda indorum salute («Corpus Hispanorum de Pace», vols. XXIII y XXIV), Madrid, Consejo Superior de Investigaciones Científicas, 1984 (vol. 1), 1987 (vol. 2). Se citará por esta edición bilingüe, señalando libro, capítulo, parágrafo -si procede-, y volumen y páginas del texto latino.

37 Aunque Acosta seguramente estaba enterado de la controversia de Valladolid, no es seguro que conociera sus textos fundamentales (el Demócrates Segundo de Sepúlveda y la Apología de Las Casas) y es improbable que conociera la restante obra de Las Casas. Cfr. PAGDEN, The fall of natural man, 146.

38 «Barbaros autem probati auctores eos esse definiunt, qui a recta ratione et hominum communi consuetudine abhorrent». ACOSTA, De procuranda indorum salute, Proemio, vol. 1, 60. Cfr. TOMÁS DE AQUINO, Super I Cor., cap. 14, lect. 2: «Nota quod barbari, secundum quosdam, dicuntur illi, quorum idioma discordat omnino a Latino. Alii vero dicunt quod quilibet extraneus est barbarus omni alii extraneo, quando scilicet non intelligitur ab eo. Sed hoc non est verum, quia, secundum Isidorum, Barbaria est specialis natio [...]. Sed secundum quod verius dicitur, barbari proprie dicuntur illi, qui in virtute corporis vigent, in virtute rationis deficiunt et sunt quasi extra leges et sine regimine iuris». SANCTI THOMAE DE AQUINO, Super I Epistolam B. Pauli ad Corinthios lectura (bttp://wnw. corpusthomisticum.org/c1v.btml\#87675, consultado el 11 de junio de 2012).

39 ACOSTA, De procuranda indorum salute, Proemio, vol. 1, 60-68.
} 
En primer lugar, estarían aquellos que, al gozar de un régimen político estable y bien organizado, de leyes, monumentos públicos, comercio y, sobre todo, el cultivo de las letras, no se apartan considerablemente de la recta razón. Entre ellos están los chinos y japoneses, que han desarrollado civilizaciones donde se cultivan las artes y letras y en las que hay academias, magistrados respetables y espléndidas ciudades. Aunque disientan en muchas cosas de la ley natural, ellos deben ser llamados al evangelio como lo fueron en otro tiempo griegos y romanos, a saber, valiéndose de su propia razón y su considerable sabiduría humana. Si se emplean la fuerza y el poder, se les apartará totalmente de la ley cristiana.

Hay una segunda clase de bárbaros que, aunque no usan las letras, tienen magistrados, gobierno, administración pública, culto religioso y cierta norma de comportamiento. Entre ellos están los mexicanos y peruanos, que tenían instituciones y leyes y suplieron, además, la falta de escritura con instrumentos muy ingeniosos como los quipus. Pero en muchas costumbres se desviaron gravemente de la ley natural, por lo que parece necesario poner bajo la jurisdicción de príncipes o magistrados cristianos a los que de entre ellos se conviertan al evangelio. En cuanto a su educación, Acosta recomienda, basado en su experiencia americana, el método que veremos enseguida.

La tercera clase se caracteriza por la ausencia de instituciones de cualquier tipo y de todo aquello que conforma a la vida civilizada. A esta clase de bárbaros pertenecen pueblos salvajes como los caribes, aficionados a comer carne humana, y otros menos feroces pero entregados a una vida disipada y licenciosa. A éstos hay que instruirlos primeramente para ser hombres, educándolos como a niños. Si voluntariamente se dejan enseñar, cuánto mejor; si no, hay que hacerles alguna fuerza o presión honesta para que cumplan sus obligaciones humanas y adopten un modo de vida civil ${ }^{40}$.

Las medidas convenientes para la promoción de los indios deben aplicarse, entonces, dependiendo de las necesidades educativas de cada grupo. La adaptación pedagógica a la condición de los indios es tema recurrente en el De procuranda indorum

\footnotetext{
40 «Hos omnes homines aut vix homines humana docere oportet, ut homines esse discant, tum puerorum more instituere. Et si quidem blanditiis sponte ad meliora ducantur, bene; sin minus, deserendi non sunt: sed si adversus salutem suam proterviant et in magistros medicosque suos insaniant, per potentiam et honestam vim quandam, ne Evangelium impediant, coercendi sunt, et in officio continendi, quos de sylvis transferri ad urbes et humanam vitam, et quodam modo invitos ad regnum introire compellere expediet». ACOSTA, De procuranda indorum salute, Proemio, vol. 1, 68. Cfr. Lucas 14, 23: «Et ait Dominus servo: Exi in vias et sepes; et compelle intrare ut impleatur domus mea».
} 
salute. Se trata de un tema exigido, de entrada, por la convicción acostiana en la intrínseca educabilidad de la naturaleza humana ${ }^{41}$. Pero es también un asunto de eficacia misional: a los indios se les debe enseñar a su paso, repitiendo constantemente enseñanzas sencillas, acomodadas a su capacidad y evitando sutilezas ${ }^{42}$. En lo posible y cuando la materia lo permita, hay que recurrir a imágenes ${ }^{43}$ y apelar a la experiencia de los oyentes ${ }^{44}$. Nada de esto implica un rebajamiento para el maestro, por ilustre o docto que éste sea: como recomendara San Agustín, él ha de revivir lo que enseña en el discípulo y aprenderlo de nuevo en él, como quien muestra una ciudad o un paisaje que ya conoce a un amigo y, al hacerlo, renueva el gozo de su contemplación y hasta descubre aspectos insospechados. La enseñanza, así, no genera tedio aunque sea repetitiva y elemental ${ }^{45}$.

Además de enseñar de modo adecuado a la condición y capacidad de los indios, Acosta hace algunas observaciones sobre el uso y sentido del castigo. Para que éste cumpla su función correctiva, el educador debe exponer claramente las razones del castigo y utilizarlo únicamente como medida disciplinar para el bien del discípulo, nunca para vengar ofensas hechas a su persona. En cualquier caso, el castigo debe rezumar clemencia paternal y comprensión, más que severidad o rigor. En definitiva, el amor sincero es el criterio por el que se ha de determinar cuándo hay que perdonar y cuándo, cómo y en qué medida castigar ${ }^{46}$.

Finalmente, el educador debe apoyarse en la ley natural, conocida por todos los hombres, para inculcar buenas costumbres, y ser él mismo, en todo momento, ejemplo de integridad, seriedad y buena conducta ${ }^{47}$. Hay que conservar, sin embargo, aquellas costumbres indígenas que vayan de acuerdo a esta ley natural, sin intentar cambiar de tajo los modos de vida ancestrales de los indios. Y aquellas costumbres o leyes que contraríen el derecho natural, no han de ser abolidas sin más -lo que resultaría difícil y acarrearía

\footnotetext{
${ }^{41}$ ACOSTA, De procuranda indorum salute, I, c. 8, vol. 1, 148-156; IV, c. 4, \$2, vol. 2, 26-28.

42 «Neque enim verendum est ne illos repetitione offendat, neque tam isti indigent magnis et exquisitis orationibus, quam quibusdam facilioribus accomodatis, iisque saepius repetitis». ACOSTA, De procuranda indorum salute, IV, c. 9, \$3, vol. 2, 80. Cfr. ibid., V, c. 15, \$4, vol. 2, 296-298.

${ }^{43}$ ACOSTA, De procuranda indorum salute, V, c. 4, \$9, vol. 2, 220.

${ }^{44}$ ACOSTA, De procuranda indorum salute, V, c. 10, \$5, vol. 2, 264.

45 ACOSTA, De procuranda indorum salute; IV, c. 21, \$2-3, vol. 2, 158-166. Cfr. SAN AGUSTÍN, De catechizandis rudibus, nn. 14,15 y 17 (bttp://sedecgdl.blogspot.mx/2011/09/de-catechizandis-rudibus-primeraparte.btml, consultado el 25 de junio de 2012). David Burgaleta ha señalado las influencias humanistas y jesuíticas - especialmente, de la «teología mística» del P. Jerónimo Nadal- en la pedagogía de Acosta; DAVID BURGALETA, José de Acosta, S.J. (1540-1600). His Life and Thought, Chicago, Loyola, 1999, 73-77. 46 ACOSTA, De procuranda indorum salute, IV, c. 20, vol. 2, 152-156; cfr. ibid., I, c. 7, \$5, vol. 1, 146-148.

47 ACOSTA, De procuranda indorum salute, IV, c. 17, vol. 2, 128-134; V, c. 13, \1, vol. 2, 286 y \5, vol. 2, 290.
} 
muchos inconvenientes- sino sustituidas por otras parecidas, más aceptables. Acosta propone, en este espíritu de respeto, que se permitan los festejos solemnes y convites en las plazas, como ya prescribían las leyes de los incas, para disuadir a los indios de los desmanes que, en privado y sin supervisión de la autoridad pública, pudieran cundir más fácilmente ${ }^{48}$.

\section{Conclusión}

Bajo las tipologías de la barbarie que proponen Las Casas y Acosta, yace el factor común del apartamiento de la ley natural, por la que ellos entienden el dictamen de la razón común a todos los hombres, en virtud del cual éstos se saben obligados a obrar según las exigencias de su propia naturaleza racional y social. La educación, en cuanto tendiente a cultivar el respeto a esta ley, excede así el carácter de mera aculturación o, en este caso, «españolización», pues toma como criterio un elemento que, aunque inscrito en la esfera de lo cultural -variable y particular-, la trasciende para instalarse en el ámbito de lo humano sin más. Al reconocer la índole racional del sujeto de la educación y propugnar el empleo únicamente de medios adecuados a ella, estos autores son capaces de valorar y exigir respeto a las particularidades culturales de los indios, por considerarlas manifestaciones legítimas de la racionalidad humana, aun siendo distintas de las españolas o europeas. Pues a estas particularidades subyace la humanidad común, la cual conlleva una serie de exigencias irrenunciables en el ámbito ético y político ${ }^{49}$ que dieron forma a las controversias indianas durante los Siglos de Oro. La educación como la entendieron Las Casas y Acosta, o sea, como perfeccionamiento progresivo de las facultades humanas, no consistió, entonces, en una simple dinámica de imposición cultural o «imperialista», sino en un proceso de integración humana y social desde la perspectiva de una concepción

\footnotetext{
48 ACOSTA, De procuranda indorum salute, III, c. 24, \$1-2, vol. 1, 586-590; cfr. ibid., V, c. 11, \4, vol. 2, 274276.

49 «La unidad del género humano [para Las Casas] -comenta M. Beuchot- se preserva en lo esencial, en lo substancial, y sólo pueden aceptarse entre los pueblos diferencias accidentales, que no disuelven la unidad básica y que sólo manifiestan los contextos heterogéneos en los que se realiza la especie humana. Y, por ende, son diferencias que -en cuanto tuvieran de inconvenientes- podrían ser reducidas a esa unidad e igualdad fundamental; con ello, los deberes y derechos del hombre son los mismos. Donde se ve en toda su magnitud el talento antropológico de Las Casas es justamente en el estudio de estas diferencias accidentales que no diluyen la unidad esencial. Son diferencias culturales que no menoscaban la unidad e igualdad de la naturaleza humana». BEUCHOT, Los fundamentos de los derechos humanos, 36.
} 
humanista y cristiana de la vida. Por ello, no en balde se ha puesto de relieve, en las últimas décadas, el papel que desempeñó el pensamiento español de este periodo en el proceso de maduración de la moderna doctrina de los derechos humanos ${ }^{50}$.

\footnotetext{
'Universidad de Monterrey (Av. Ignacio Morones Prieto, 4500 Pte., Garza García, Nuevo León, 66238 México). Correo electrónico: victorzorrillagarza@yahoo.com
}

\footnotetext{
50 BRIAN TIERNEY, The Idea of Natural Rights. Studies in Natural Rights, Natural Law, and Church Law, 1550-1625, Grand Rapids-Cambridge, Eerdmans, 2001, 255-287 (especialmente, 286-287). A propósito del pensamiento del virreinato novohispano -aunque el juicio puede extenderse a todo el pensamiento español aurisecular-, Mauricio Beuchot explica que «de manera contraria a una opinión muy extendida, la filosofía del virreinato no fue una especulación estéril, desentendida de los problemas reales o solapadora de la injusticia y la opresión, sino una que tuvo en muchos de sus cultivadores el ser fermento para la búsqueda de la justicia, la liberación y la paz. Ellos [...] corrieron la suerte de la mayoría de los filósofos sociales, a saber, el no ser escuchados por los hombres de su tiempo [...]. Pero fue una búsqueda real de la justicia y el bien común, y ya es tiempo de arrancar los prejuicios historiográficos que han impedido ver estos valores». MAURICIO BEUCHOT, Filosofía social de los pensadores novohispanos. La búsqueda de la justicia social y el bien común en tiempos del virreinato, México, Instituto Mexicano de Doctrina Social Cristiana, 2000, 6. Sin detrimento de que esta crítica abarque a varios autores (Beuchot no menciona a ninguno), habría que incluir entre ellos a Anthony Pagden; cfr. su precitado libro The fall of natural man, 2-3.
} 